\title{
Intercalator-assisted plasma-liquid technology: an efficient exfoliation method for few-layer two-dimensional materials
}

\author{
Hao Huang ${ }^{1,2 \dagger}$, Ming Gao ${ }^{1,2 \dagger}$, Jiahong Wang ${ }^{1,2,3}$, Paul K. Chu ${ }^{3}$, Yifan Huang ${ }^{1,2^{*}}$ and Xue-Feng Yu ${ }^{1,2^{*}}$
}

Few-layer two-dimensional (2D) materials have attracted enormous interest since 2004 when graphene was successfully exfoliated from graphite by mechanical exfoliation [1]. In recent years, the burgeoning 2D family with unique and novel properties have found new applications in a myriad of fields including electronics, optoelectronics, catalysis, energy, and biomedicine [2-4]. However, in order to be commercially viable, a mass fabrication technique to synthesize few-layer 2D materials with high quality is critical. The typical large-scale fabrication strategy for few-layer $2 \mathrm{D}$ materials is liquid exfoliation from the bulk counterparts with a layered structure [5]. Although the exfoliation by chemical oxidation can produce graphene oxide from graphite on a large scale [6], functional groups are generally introduced and defects are produced [7]. Ultrasonic/shear liquid exfoliation applies to most $2 \mathrm{D}$ materials but requires a long processing time (generally several hours) and often obtains small and thick sheets. Modified physical exfoliation methods such as ultrasonic-ball milling and intermediate-assisted grinding exfoliation improve the yield and quality of the exfoliated materials; however, a further purification is needed $[8,9]$. Recently, methods based on electrochemical technology (ET) have been proposed [10-18]. Generally, intercalator-assisted electrochemical technique (IA-ET) with intercalators such as quaternary ammonium salts or $\mathrm{Li}^{+}$complexes enables the intercalation of ions/molecules into the interlayer, leading to the expansion of the bulk layered materials, thus facilitating subsequent exfoliation into few-layer sheets $[11,13,15]$.
However, IA-ET exfoliation often damages the structure and alters the properties of the materials due to the residual intercalators [16]. Considering the complexity and variety of $2 \mathrm{D}$ materials, it is highly desired to develop a new exfoliation method for mass production of different types of few-layer 2D materials.

Plasma processing is a common method in surface modification, surface etching, and thin film deposition due to the production of abundant active species [19-23]. The plasma-liquid technology (PLT) has been adopted for nanomaterials synthesis and doping because it can effectively transfer the active species to the liquid through the plasma-liquid interface for the chemical reactions $[20,24,25]$. Compared with ET, PLT can produce more active species and trigger various charge transfer reactions such as quick decomposition and polymerization of organic molecules. Furthermore, PLT only requires a simple and economical atmospheric-pressure plasma system operated under ambient conditions. Our previous work has demonstrated that PLT enables scalable production of phosphorene without additional intercalators [20]. However, it is difficult to extend the use of PLT without intercalators to other types of $2 \mathrm{D}$ materials.

Herein, an intercalator-assisted PLT (IA-PLT) was designed and applied for the synthesis of $2 \mathrm{D}$ materials. $\mathrm{LiCl}$ served as the intercalator to rapidly expand graphite paper, leading to the formation of graphene with few defects on a large scale. The IA-PLT exfoliation process and the corresponding intercalation mechanism were investigated and compared with that of the traditional IA-ET method.

\footnotetext{
${ }^{1}$ Shenzhen Engineering Center for the Fabrication of Two-Dimensional Atomic Crystals, Shenzhen Institutes of Advanced Technology, Chinese Academy of Sciences, Shenzhen 518055, China

${ }^{2}$ University of Chinese Academy of Sciences, Beijing 100049, China

${ }^{3}$ Department of Physics, Department of Materials Science and Engineering, and Department of Biomedical engineering, City University of Hong Kong, Tat Chee Avenue, Kowloon, Hong Kong, China

These authors contributed equally to this paper.

* Corresponding authors (emails xf.yu@siat.ac.cn (Yu XF); yf.huang@siat.ac.cn (Huang Y))
} 
The IA-PLT which can be readily extended to the production of other types of $2 \mathrm{D}$ material such as few-layer $2 \mathrm{H}-\mathrm{MoS}_{2}$ possesses a number of merits such as rapid expansion, high-quality few-layer products without introducing intermediates or functional groups, and outstanding expandability and controllability.

The IA-PLT-induced expansion process with graphite paper was first studied. The IA-PLT system comprises a high-voltage power supply, two electrodes and a cell filled with exfoliation solution [20]. The plasma generated by the high-voltage from a stainless tube upon the solution served as the anode and the cathode was the immersed graphite paper. The exfoliation solution was prepared by dissolving $\mathrm{LiCl}$ in dimethylformamide (DMF, $4 \mathrm{mg} \mathrm{mL}^{-1}$ ) and the expansion process completed in 4 min (Video S1). During the exfoliation, a large amount of bubbles can be observed on the graphite paper (Fig. S1). Fig. 1a displays the photographs of the graphene-DMF dispersions produced by IA-PLT. Owing to the rapid IA-PLT reaction, four bottles (total of $3.6 \mathrm{~L}$ ) of the graphene-DMF dispersions $\left(0.8 \mathrm{mg} \mathrm{mL}^{-1}\right)$ can be produced in $12 \mathrm{~h}$. The graphene product was characterized by atomic force microscopy (AFM), scanning electron microscopy (SEM), transmission electron microscopy (TEM), and high-resolution TEM (HR-TEM). Fig. $1 \mathrm{~b}$ and $\mathrm{c}$ show that the formation of few-layer graphene with a thickness dis- tribution ranging from 2 to $9 \mathrm{~nm}$ corresponding to $3-12$ layers [26]. The lattice spacing of $0.21 \mathrm{~nm}$ shown in the HR-TEM image (inset in Fig. 1c), is consistent with the (100) plane of graphene. The SEM images (Fig. S2) show a clear surface of the graphene with a lateral size distribution from hundreds of nanometers to several micrometers. Fig. 1d depicts the high-resolution Raman spectrum of a single graphene sheet and the D band at $1350 \mathrm{~cm}^{-1}$, G band at $1583 \mathrm{~cm}^{-1}$, and $2 \mathrm{D}$ band at $2720 \mathrm{~cm}^{-1}$ are observed [25-28]. The D band reflects the disorders within $\mathrm{sp}^{2}$-bonded carbon regions caused by defects and the intensity ratio $I_{\mathrm{D}} / I_{\mathrm{G}}$ is generally used to indicate the degree of defects at the in-plane area of graphene [29]. Here, $I_{\mathrm{D}} / I_{\mathrm{G}}$ of the IA-PLT-exfoliated graphene is only 0.02 , which is much less than that (0.160.95) of graphene reported previously [26], indicating that the IA-PLT-exfoliated graphene has high quality.

X-ray photoelectron spectroscopy (XPS) was conducted to determine the chemical composition of the IA-PLTexfoliated graphene. As shown in Fig. 1e, a weak O 1s peak is found and the atomic ratio of carbon and oxygen $(\mathrm{C} / \mathrm{O})$ is 31.5 , which is larger than those $(9.26-21.2)$ of graphene synthesized before [26]. The high-resolution $\mathrm{C}$ 1s peak indicates four types of carbon bonds by data fitting (Fig. 1f). The peaks at 284.5, 284.8, 285.6 and $287.1 \mathrm{eV}$ can be assigned to $\mathrm{C}-\mathrm{C}, \mathrm{C}-\mathrm{H}, \mathrm{C}-\mathrm{N}$, and $\mathrm{C}=\mathrm{O}$
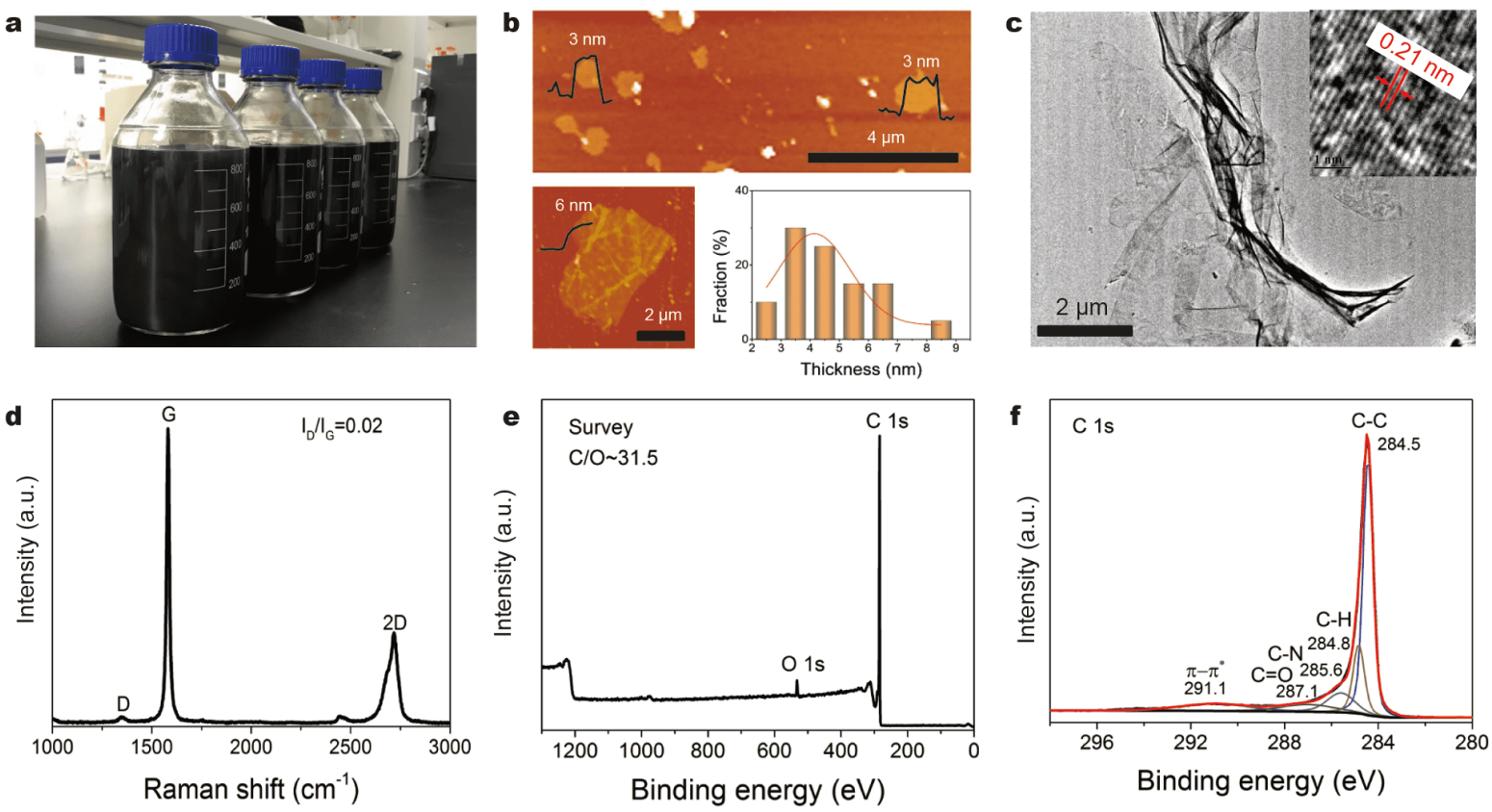

Figure 1 Characterization of the IA-PLT-exfoliated graphene: (a) photographs of the graphene-DMF dispersions; (b) AFM images and thickness distribution of graphene (at least 100 sheets were measured); (c) TEM image and HR-TEM image (inset); (d) Raman scattering spectrum; (e, f) XPS survey and C 1s spectra. 
bonds, respectively $[27,29]$ and that at $291.1 \mathrm{eV}$ is related to $\pi-\pi^{*}$ which indicates the existence of a conjugated aromatic structure. The additional carbon bonds (such as $\mathrm{C}-\mathrm{H}, \mathrm{C}-\mathrm{N}, \mathrm{C}=\mathrm{O}$ ) are attributed to the residual solvent from the exfoliation and washing processes [27,29]. Hence, the large $\mathrm{C} / \mathrm{O}$ ratio indicates negligible oxidation during the IA-PLT exfoliation process.

To explore the mechanism of the IA-PLT-induced exfoliation, graphite papers with different expansion degrees were examined by SEM and X-ray diffraction (XRD). It is known that the intercalation and functional groups cause the expansion during the ET-exfoliation, and the expansion degrees are related to the residual intermediates or functional groups, which result in the shift of XRD peaks [10-18,30,31]. Photographs inset in Fig. 2 clearly show the expanded graphite paper with small and large expansion degrees and Fig. 2a-c show the cross sections of the compact graphite paper and wrinkled expansion samples, especially the enlarged spaces, indicating that the van der Waals (vdW) force between the layers has been greatly weakened. As shown in Fig. 2d, two typical diffraction peaks originating from graphite at around $26.5^{\circ}(002)$ and $54.7^{\circ}(004)$ can be found from all the samples and the sharp diffraction peaks can be attributed to the restacking of the expanded layers. In traditional IA-ET exfoliation of graphite, the (002) peak generally shifts to a small angle due to the intercalation and formation of intermediate compounds [30,31]. In contrast, during IA-PLT expansion, the (002) peak becomes slightly broadened and does not shift significantly, indicating that there is no or very little intercalator residue in the layer space. In addition, no peak belonging to Li compounds appears in the XRD spectra and no XPS signal of $\mathrm{Cl}$ or Li element can be found (Fig. S3), suggesting that no or few $\mathrm{Li}$ compounds are formed during the IA-PLT-induced exfoliation. In the control experiment in which DMF is exchanged with water or $\mathrm{LiCl}$ with $\mathrm{HCl}$, no expansion can be observed. However, when $\mathrm{Li}^{+}$is replaced by other metal ions such as $\mathrm{Na}^{+}, \mathrm{K}^{+}, \mathrm{Mg}^{2+}, \mathrm{Ca}^{2+}$ and $\mathrm{Sr}^{2+}$, similar IA-PLT-induced expansion can be observed. Fig. $\mathrm{S} 4$ shows the graphene products synthesized with $\mathrm{CaCl}_{2}$ and $\mathrm{SrCl}_{2}$.

The possible IA-PLT exfoliation mechanism was proposed (Fig. 3). On account of the abundant electrons and active species generated by the plasma, chemical reactions initiate at the interface between the plasma and liquid phase simultaneously as a result of the transport processes $[23,24]$. As described previously, the DMF $\left(\mathrm{C}_{3} \mathrm{H}_{7} \mathrm{NO}\right)$ molecules can decompose into cations $\left(\mathrm{C}_{3} \mathrm{H}_{8} \mathrm{~N}^{+}, \mathrm{C}_{2} \mathrm{H}_{8} \mathrm{~N}^{+}\right.$, $\mathrm{C}_{2} \mathrm{H}_{6} \mathrm{~N}^{+}, \mathrm{C}_{2} \mathrm{H}_{4} \mathrm{~N}^{+}$, and $\mathrm{H}^{+}$) with plasma, which together with the solvated metal ion/DMF complexes move to the cathodic graphite paper under the electric field [20]. The
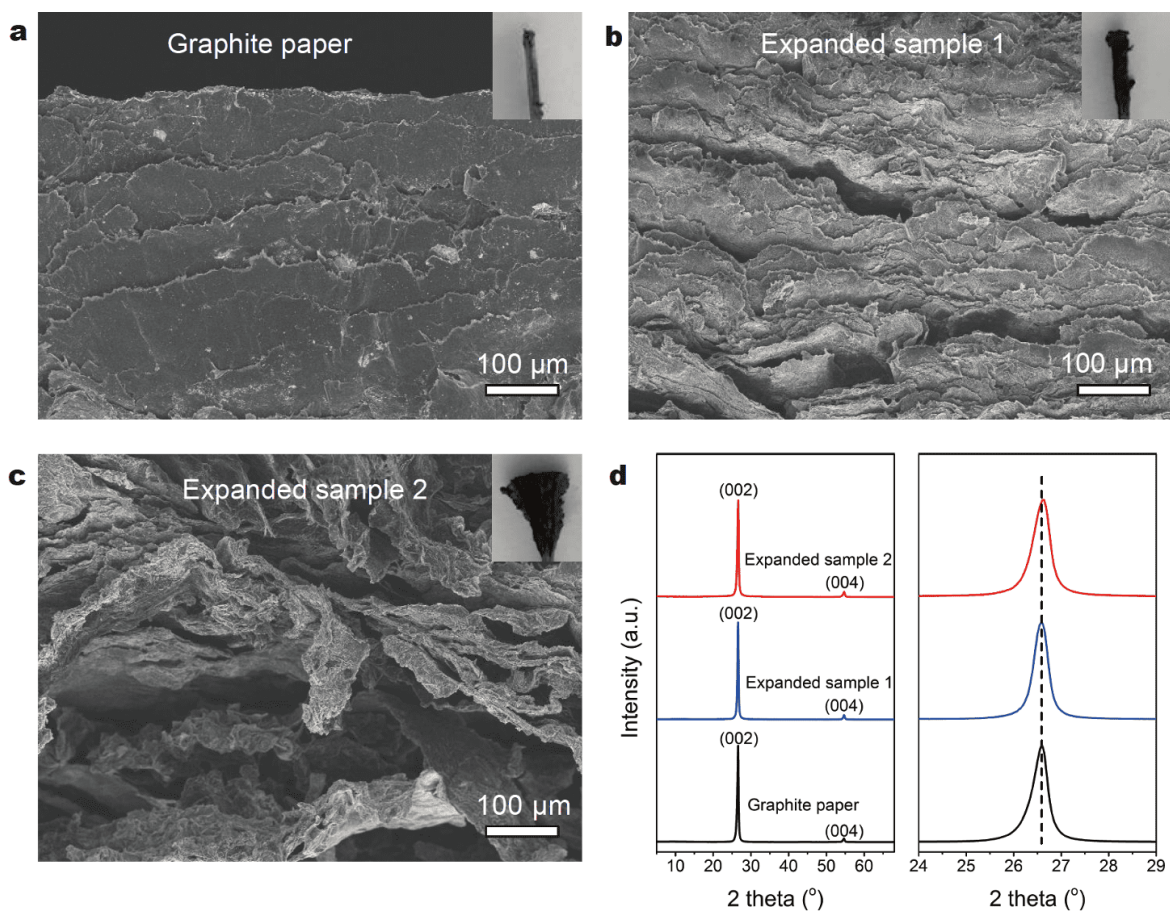

Figure $2(a-c)$ Cross-section SEM images, inset photographs and (d) XRD spectra and enlarged specific region of the graphite paper in different expansion degrees. 


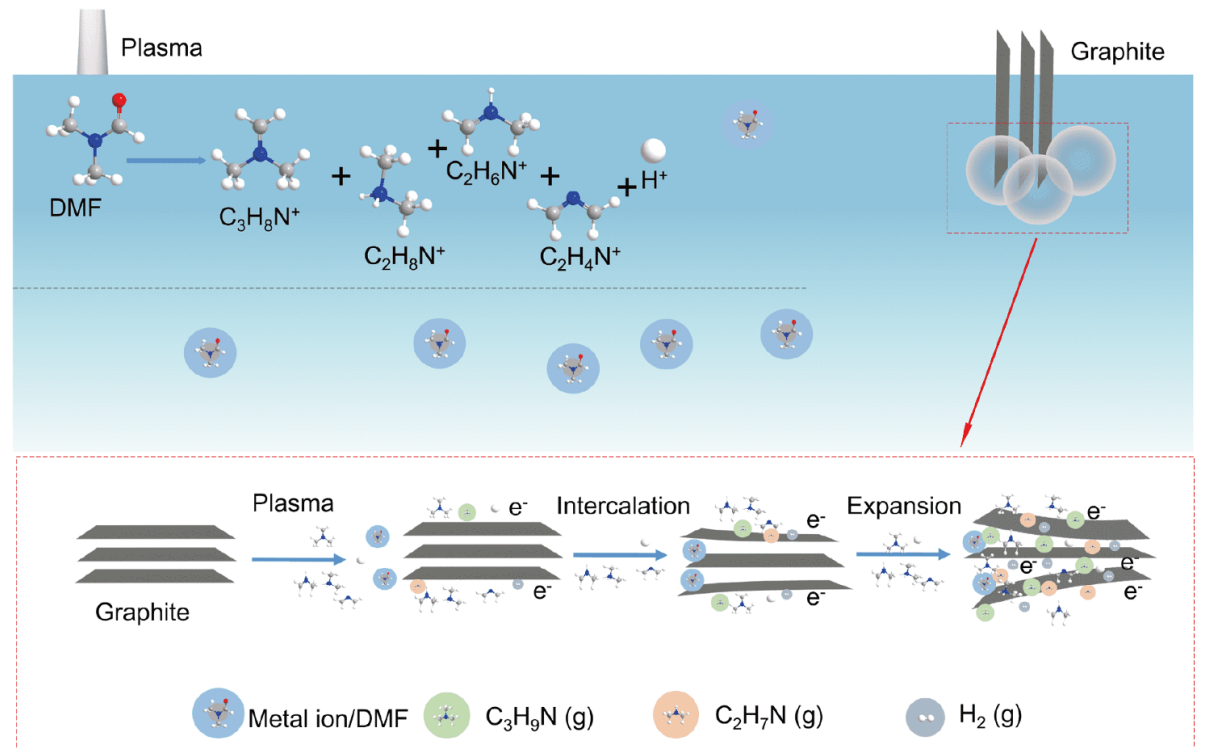

Figure 3 Schematic of the IA-PLT exfoliation process in graphite paper.

metal ions quickly receive electrons from the graphite cathode and transfer to the surrounding decomposed DMF species. The interaction impacts the boundaries of graphite to weaken the vdW force between layers [18]. Subsequently, the DMF decomposed cationic species enter the open graphite layer to further weaken the vdW force and quick electron transfer leads to efficient conversion of the cations to gases including $\mathrm{C}_{3} \mathrm{H}_{9} \mathrm{~N}, \mathrm{C}_{2} \mathrm{H}_{7} \mathrm{~N}$, and $\mathrm{H}_{2}$, which expand the graphite, resulting in exfoliation.

The IA-PLT exfoliation method was compared with the conventional IA-ET method which involves an electric field and intercalator. Control experiments were performed by changing the plasma anode to a platinum wire anode generally used in ET exfoliation. Only weak expansion of graphite paper can be observed for IA-ET with $\mathrm{LiCl}$ or other metal chlorides as the intercalator. In fact, ET cannot decompose DMF efficiently (Fig. S5). Moreover, metal ions such as $\mathrm{Li}^{+}$and $\mathrm{Ca}^{2+}$ in the IA-ET exfoliation tend to react with graphite to form complexes on the surface [30], while this phenomenon is not observed from IA-PLT (Fig. S6). Metal ion intercalation in IA-ET exfoliation is described as an ion-electron transfer reaction and water is requisite in the hydration process. Therefore, highly active pure $\mathrm{Li}$ foil or $\mathrm{Li}$ compounds such as $\mathrm{LiClO}_{4}, \mathrm{LiBF}_{4}$ and $\mathrm{C}_{4} \mathrm{H}_{9} \mathrm{Li}$, are required to enable exfoliation, but the use of $\mathrm{Li}$ foils or $\mathrm{Li}$ compounds is dangerous and Li intermediates are often formed [32]. In contrast, owing to the mass of the active species and quick electron transfer induced by the plasma, IA-PLT is more efficient than IA-ET because the former technique requires safe metal ion intercalators only. In addition, IAPLT involves no residual metal complexes, thus eliminating the possible influence of intercalators on the properties of the final materials.

To investigate the versatility, IA-PLT was applied to exfoliate another type of 2D materials, molybdenum disulfide $\left(\mathrm{MoS}_{2}\right)$. As a typical transition-metal dichalcogenide (TMD), $\mathrm{MoS}_{2}$ crystal has the $2 \mathrm{H}$-phase and the single layer is composed of a three-atom-thick hexagon of Mo-S-Mo (Fig. S7a). The traditional IA-ET method utilizing $\mathrm{Li}^{+}$intercalation generally leads to the phase transition of $\mathrm{MoS}_{2}$ from $2 \mathrm{H}$ to $1 \mathrm{~T}$ accompanied by the formation of the $\mathrm{Li}_{x} \mathrm{MoS}_{2}$ intermediate [33,34]. Although the quaternary ammonium (THAB) has been used for the production of $2 \mathrm{H}-\mathrm{MoS}_{2}$, it needs a long-time intercalation process with the formation of the $\left(\mathrm{THA}^{+}\right)_{x} \mathrm{MoS}_{2}{ }^{{ }^{-}}$ intermediates [35]. As shown in Fig. 4a, IA-PLT with the $\mathrm{LiCl} / \mathrm{DMF}$ solution enables full expansion of the $\mathrm{MoS}_{2}$ crystal in $10 \mathrm{~min}$ (Video S2). The expanded sample is dispersed in isopropanol (IPA) by sonication to obtain the $\mathrm{MoS}_{2}$ sheets-IPA dispersions with a dark green color. Fig. S7b shows the XRD spectra of the bulk $\mathrm{MoS}_{2}$ with different expansion degrees. Similar to graphite, the (002) plane of $\mathrm{MoS}_{2}$ shows no small angle shift and no peak belonging to $\mathrm{Li}$ compounds appears during expansion. Furthermore, $\mathrm{MoS}_{2}$ maintains the $2 \mathrm{H}$-phase during the IA-PLT-induced expansion. 

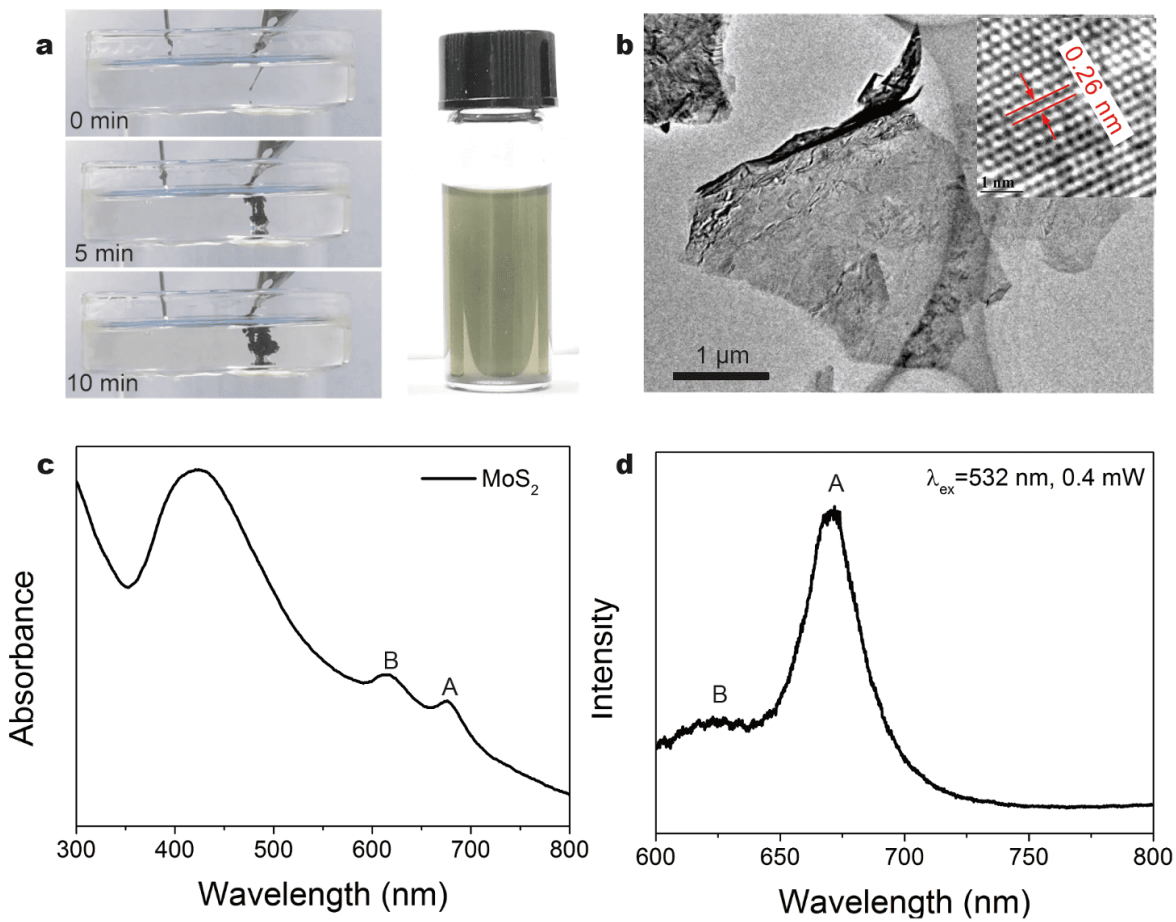

Figure 4 Characterization of the IA-PLT-exfoliated $\mathrm{MoS}_{2}$ sheets: (a) photographs showing the IA-PLT exfoliation process and the MoS 2 sheets-IPA dispersions; (b) TEM image and HR-TEM image (inset); (c) absorbance spectrum of the $\mathrm{MoS}_{2}$ sheets-IPA dispersions; (d) PL spectrum of one representative $\mathrm{MoS}_{2}$ sheet.

Fig. $4 \mathrm{~b}$ and Figs $\mathrm{S} 8$, S9a show that the $\mathrm{MoS}_{2}$ sheets have a typical thickness of about $3.2 \mathrm{~nm}$ with the lateral size between 1 and $30 \mu \mathrm{m}$. The HR-TEM image shows a lattice space of $0.26 \mathrm{~nm}$ ascribed to the (100) plane. The Raman spectrum in Fig. $S 9 b$ reveals prominent $E_{2 g}^{1}$ and $A_{1 g}$ phonons at 380 and $403 \mathrm{~cm}^{-1}$, respectively, consistent with those of the previously reported few-layer $\mathrm{MoS}_{2}$ [34]. The Mo 3d XPS spectrum in Fig. S9c shows peaks at around 229.0 and $232.1 \mathrm{eV}$ associated with $\mathrm{Mo}^{4+} 3 \mathrm{~d}_{5 / 2}$ and $\mathrm{Mo}^{4+} 3 \mathrm{~d}_{3 / 2}$ of the $2 \mathrm{H}-\mathrm{MoS}_{2}$, respectively [33]. The S $2 \mathrm{p}$ doublets at $162.9 \mathrm{eV}\left(\mathrm{S} 2 \mathrm{p}_{1 / 2}\right)$ and $161.7 \mathrm{eV}\left(\mathrm{S} 2 \mathrm{p}_{3 / 2}\right)$ are observed from Fig. S9d. The XPS results thus confirm successful preparation of the $2 \mathrm{H}$-phase few-layer $\mathrm{MoS}_{2}$ sheets by IA-PLT. The optical properties of the $\mathrm{MoS}_{2}$ sheets were determined. As shown in Fig. 4c, the A and B exciton peaks from the $\mathrm{K}$ point of the Brillouin zone appear at 676 and $615 \mathrm{~nm}$, respectively, and the convoluted $\mathrm{C}$ and $\mathrm{D}$ excitonic peaks are located at around $425 \mathrm{~nm}$. Photoluminescence (PL) is observed from a typical $\mathrm{MoS}_{2}$ sheet deposited on the $\mathrm{Si} / \mathrm{SiO}_{2}$ substrate with a $532 \mathrm{~nm}$ laser and Fig. $4 \mathrm{~d}$ shows the PL spectrum of the $2 \mathrm{H}-\mathrm{MoS}_{2}$ sheets which agrees well with the mechanically exfoliated samples reported previously [36]. The PL peak at $670 \mathrm{~nm}$ and a small shoulder at about $620 \mathrm{~nm}$ are observed.

In summary, an efficient IA-PLT exfoliation method for the production of high-quality $2 \mathrm{D}$ materials such as graphene and $\mathrm{MoS}_{2}$ is demonstrated. By using graphite paper as the raw materials and $\mathrm{LiCl}$ as the intercalator, large-scale production of few-defect graphene with $I_{\mathrm{D}} / I_{\mathrm{G}}$ of 0.02 and $\mathrm{C} / \mathrm{O}$ ratio of 31.5 is demonstrated and the efficiency is much higher than that of previously reported exfoliation techniques. This technique can be extended to the rapid production of few-layer metal sulfide $(2 \mathrm{H}$ $\mathrm{MoS}_{2}$ ). Owing to the special plasma-liquid interface reactions created by the plasma, IA-PLT has many merits such as free choice of safe metal ion intercalators, almost no residual intercalator, high-quality (few defects) products, rapid expansion, high production yield, as well as outstanding controllability and expandability. These advantages cannot be matched by other current techniques and hence, IA-PLT has great potential in the production of different types of few-layer 2D materials.

Received 24 March 2020; accepted 31 May 2020;

published online 5 August 2020

1 Novoselov KS, Geim AK, Morozov SV, et al. Electric field effect in atomically thin carbon films. Science, 2004, 306: 666-669 
2 Mounet N, Gibertini M, Schwaller P, et al. Two-dimensional materials from high-throughput computational exfoliation of experimentally known compounds. Nat Nanotech, 2018, 13: 246-252

3 Bonaccorso F, Colombo L, Yu G, et al. Graphene, related twodimensional crystals, and hybrid systems for energy conversion and storage. Science, 2015, 347: 1246501-41

4 Yi Y, Yu XF, Zhou W, et al. Two-dimensional black phosphorus: Synthesis, modification, properties, and applications. Mater Sci Eng-R-Rep, 2017, 120: 1-33

5 Kang J, Sangwan VK, Wood JD, et al. Solution-based processing of monodisperse two-dimensional nanomaterials. Acc Chem Res, 2017, 50: 943-951

6 Park S, Ruoff RS. Chemical methods for the production of graphenes. Nat Nanotech, 2009, 4: 217-224

7 Pei S, Cheng HM. The reduction of graphene oxide. Carbon, 2012, 50: $3210-3228$

8 Shi D, Yang M, Chang B, et al. Ultrasonic-ball milling: A novel strategy to prepare large-size ultrathin 2D materials. Small, 2020, 16: 1906734

9 Zhang C, Tan J, Pan Y, et al. Mass production of 2D materials by intermediate-assisted grinding exfoliation. Natl Sci Rev, 2020, 7: 324-332

$10 \mathrm{Su} \mathrm{CY}, \mathrm{Lu} \mathrm{AY}, \mathrm{Xu} \mathrm{Y}$, et al. High-quality thin graphene films from fast electrochemical exfoliation. ACS Nano, 2011, 5: 2332-2339

11 Zeng Z, Yin Z, Huang X, et al. Single-layer semiconducting nanosheets: high-yield preparation and device fabrication. Angew Chem Int Ed, 2011, 50: 11093-11097

$12 \mathrm{Wu} \mathrm{W}$, Zhang $\mathrm{C}$, Hou S. Electrochemical exfoliation of graphene and graphene-analogous 2D nanosheets. J Mater Sci, 2017, 52: 10649-10660

13 Huang Z, Hou H, Zhang Y, et al. Layer-tunable phosphorene modulated by the cation insertion rate as a sodium-storage anode. Adv Mater, 2017, 29: 1702372

14 Cao J, He P, Mohammed MA, et al. Two-step electrochemical intercalation and oxidation of graphite for the mass production of graphene oxide. J Am Chem Soc, 2017, 139: 17446-17456

15 Yang S, Brüller S, Wu ZS, et al. Organic radical-assisted electrochemical exfoliation for the scalable production of high-quality graphene. J Am Chem Soc, 2015, 137: 13927-13932

16 Liu N, Kim P, Kim JH, et al. Large-area atomically thin $\mathrm{MoS}_{2}$ nanosheets prepared using electrochemical exfoliation. ACS Nano, 2014, 8: 6902-6910

17 Wang $\mathrm{C}, \mathrm{He} \mathrm{Q}$, Halim U, et al. Monolayer atomic crystal molecular superlattices. Nature, 2018, 555: 231-236

18 Wang J, Manga KK, Bao Q, et al. High-yield synthesis of few-layer graphene flakes through electrochemical expansion of graphite in propylene carbonate electrolyte. J Am Chem Soc, 2011, 133: 88888891

19 Neyts EC, Ostrikov KK, Sunkara MK, et al. Plasma catalysis: synergistic effects at the nanoscale. Chem Rev, 2015, 115: 1340813446

20 Huang H, Gao M, Kang Y, et al. Rapid and scalable production of high-quality phosphorene by plasma-liquid technology. Chem Commun, 2020, 56: 221-224

21 Li M, Liu D, Wei D, et al. Controllable synthesis of graphene by plasma-enhanced chemical vapor deposition and its related applications. Adv Sci, 2016, 3: 1600003

22 Wang Y, Zhang Y, Liu Z, et al. Layered double hydroxide nanosheets with multiple vacancies obtained by dry exfoliation as highly efficient oxygen evolution electrocatalysts. Angew Chem Int
Ed, 2017, 56: 5867-5871

23 Zhang Y, Rawat RS, Fan HJ. Plasma for rapid conversion reactions and surface modification of electrode materials. Small Methods, 2017, 1: 1700164

24 Richmonds C, Sankaran RM. Plasma-liquid electrochemistry: Rapid synthesis of colloidal metal nanoparticles by microplasma reduction of aqueous cations. Appl Phys Lett, 2008, 93: 131501

25 Yen PJ, Ting CC, Chiu YC, et al. Facile production of graphene nanosheets comprising nitrogen-doping through in situ cathodic plasma formation during electrochemical exfoliation. J Mater Chem C, 2017, 5: 2597-2602

26 Yang S, Ricciardulli AG, Liu S, et al. Ultrafast delamination of graphite into high-quality graphene using alternating currents. Angew Chem Int Ed, 2017, 56: 6669-6675

27 Hernandez Y, Nicolosi V, Lotya M, et al. High-yield production of graphene by liquid-phase exfoliation of graphite. Nat Nanotech, 2008, 3: 563-568

$28 \mathrm{Wu}$ W, Liu M, Gu Y, et al. Fast chemical exfoliation of graphite to few-layer graphene with high quality and large size via a two-step microwave-assisted process. Chem Eng J, 2020, 381: 122592

29 Paton KR, Varrla E, Backes C, et al. Scalable production of large quantities of defect-free few-layer graphene by shear exfoliation in liquids. Nat Mater, 2014, 13: 624-630

30 Cooper AJ, Wilson NR, Kinloch IA, et al. Single stage electrochemical exfoliation method for the production of few-layer graphene via intercalation of tetraalkylammonium cations. Carbon, 2014, 66: 340-350

$31 \mathrm{Wu} \mathrm{L}, \mathrm{Li} \mathrm{W}, \mathrm{Li}$ P, et al. Powder, paper and foam of few-layer graphene prepared in high yield by electrochemical intercalation exfoliation of expanded graphite. Small, 2014, 10: 1421-1429

32 Abdelkader AM, Cooper AJ, Dryfe RAW, et al. How to get between the sheets: a review of recent works on the electrochemical exfoliation of graphene materials from bulk graphite. Nanoscale, 2015, 7: 6944-6956

33 Eda G, Yamaguchi H, Voiry D, et al. Photoluminescence from chemically exfoliated $\mathrm{MoS}_{2}$. Nano Lett, 2011, 11: 5111-5116

34 Zheng J, Zhang H, Dong S, et al. High yield exfoliation of twodimensional chalcogenides using sodium naphthalenide. Nat Commun, 2014, 5: 2995

35 Lin Z, Liu Y, Halim U, et al. Solution-processable 2D semiconductors for high-performance large-area electronics. Nature, 2018, 562: 254-258

36 Splendiani A, Sun L, Zhang Y, et al. Emerging photoluminescence in monolayer $\mathrm{MoS}_{2}$. Nano Lett, 2010, 10: 1271-1275

Acknowledgements This work was supported by the National Natural Science Foundation of China (21975280), Shenzhen Science and Technology Research Funding (JCYJ20180507182530279), the Frontier Science Key Programs of Chinese Academy of Sciences (QYZDB-SSWSLH034), Guangdong Special Support Program (2017TX04C096), the Leading Talents of Guangdong Province Program (00201520), and the City University of Hong Kong Strategic Research Grants (SRG, 7005105 and 7005264).

Author contributions Huang $\mathrm{H}$ and Gao $\mathrm{M}$ conducted the experiments and measurements; Wang J, Chu PK, Huang Y discussed the data and provided suggestions; Yu XF supervised and directed the project; All authors participated the general discussion.

Conflict of interest The authors declare no conflict of interest. 
Supplementary information Experimental details and supporting data are available in the online version of the paper.

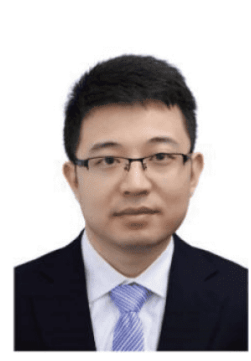

Hao Huang received his BSc degree from the University of Electronic Science and Technology of China (2012) and MSc degree from Wuhan University (2015). Now, he is a PhD candidate at Shenzhen Institutes of Advanced Technology, Chinese Academy of Sciences, China. His interests focus on the synthesis and applications of nanomaterials and $2 \mathrm{D}$ materials.

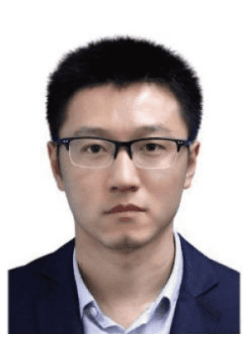

Ming Gao received his MSc degree from Donghua University (2012), and now he is a PhD candidate at Shenzhen Institutes of Advanced Technology, Chinese Academy of Sciences, China. His interests focus on the preparation and surface modification of materials with low-temperature plasma technology.

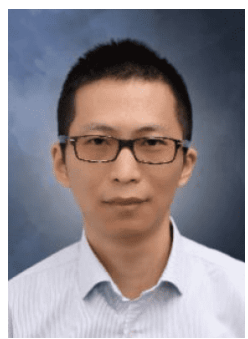

Yifan Huang received his $\mathrm{BSc}$ and $\mathrm{PhD}$ degrees from Zhejiang University, China in 2005 and 2010 respectively. Then, he joined Zhejiang University as an assistant professor, and now he is a full professor at Shenzhen Institutes of Advanced Technology, Chinese Academy of Sciences. His research interest includes non-thermal plasma generation and application.

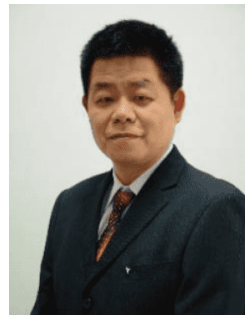

Xue-Feng Yu received his $\mathrm{PhD}$ degree in optics from Wuhan University (2008). He has been a senior research associate in the Department of Physics and Materials of City University of Hongkong. He is currently a professor at Shenzhen Institutes of Advanced Technology, Chinese Academy of Sciences, China. His interests focus on the applied materials and interfaces including the synthesis of functional materials, materials interfaces, biochips.

\section{插层剂辅助等离子体液相技术用于高效制备少层 二维材料}

黄浩 ${ }^{1,2 \dagger}$, 高明 ${ }^{1,2 \dagger}$, 王佳宏 ${ }^{1,2,3}$, 朱剑豪 ${ }^{3}$, 黄逸凡 ${ }^{1,2^{*}}$, 喻学锋 ${ }^{1,2^{*}}$

摘要 本工作提出了一种插层剂辅助的等离子体液相技术用于高 效地剥离高质量少层二维材料. 采用氯化锂为插层剂可快速剥离 石墨纸, 形成具有小 $\mathrm{D}$ 峰/G峰比(0.02) 以及大碳氧比(31.5)的石墨烯 产物. 并且, 这种方法可以拓展至高质量少层 $2 \mathrm{H}$ 相二硫化钼的制 备. 和传统的插层剂辅助电化学方法相比, 等离子体诱导产生的大 量活性粒子以及快速的电子转移, 使得插层剂辅助的等离子体液 相技术剥离的产物缺陷少且不会引入额外的基团. 这种可控的快 速剥离方法在制备其他各种类型的高质量二维材料方面都具有巨 大潜力. 